\title{
ROLE OF CARBON SOURCE FOR THE PRODUCTION OF L-GLUTAMINASE FROM ASPERGILLUS ORYZAE
}

\author{
Sunil dutt P L N S N ${ }^{1}$, Naveen $M^{1}$, Saroj Yadava ${ }^{1}$, and *Siddalingeshwara K $\mathbf{G}^{2}$ \\ ${ }^{1}$ Research and Development Centre, Bharathiar University, Coimbatore, India \\ ${ }^{2}$ Department of Studies in Microbiology, Padmshree Institute of Information Science, Bangalore, India \\ *Corresponding Author’s Email: siddha_lingeshwar@rediffmail.com
}

\begin{abstract}
Microbial glutaminases are more stable than plant and animal counterparts. In addition to it, they have also been detected in mammalian tissues where they are the major enzymes responsible for catabolic breakdown of glutamine. This study were taken up to the enhance the biosynthesis of L-glutaminase by supplementation of carbon sources were employed in range of $0.25 \%$ to $1.0 \%$. The carbon source were supplemented are glucose, fructose and lactose. In case of monosaccharides (fructose) the maximum L-glutaminase production of $494.1 \mathrm{IU}$ was observed at $1 \%$ and where as disaccharides like lactose yielded maximum L-glutaminase of $343.5 \mathrm{IU}$.
\end{abstract}

Key words: L-glutaminase, submerged fermentation, fructose, Aspergillus oryzae

\section{INTRODUCTION}

Enzymes are biocatalysts produced by the living cells to bring about specific biochemical reactions generally forming parts of the metabolic processes of the cells. Enzymes are highly specific in their action on substrates and often many different enzymes are required to bring about, by concerted action, the sequence of metabolic reactions performed by the living cell ${ }^{1}$.

Tumor cells have an absolute requirement for glutamine as a growth substrate. Glutamine is required as a precursor for bothDNA synthesis and protein synthesis. The glutamine metabolism in the tumor cells has been found to be considerably faster thannon-transformed cells $^{2}$. Exogenous supply of L-Glutaminase depletes the glutamine levels. Since the cancer cells unable tosynthesis L-Glutamine due to the lack of L-Glutamine synthase that leads to the selective death of L-Glutamine dependent tumorcells. The interest on microbial LGlutaminases found newer applications in clinical analysis and even in the manufacture ofmetabolites.

In recent years, L-glutaminase (L-glutamine amidohydrolase EC 3.5.1.2) has been studied due to their unique biotechnological versatility and their ability to catalyze a wide spectrum of bioconversion reactions of flavour compounds. Microbial glutaminases are more stable than plant and animal counterparts. In addition to it, they have also been detected in mammalian tissues where they are the major enzymes responsible for catabolic breakdown of glutamine ${ }^{3,4}$. In recent years, biomedical sciences accentuate the involvement of the enzyme 1-glutaminase and other amino acid depleting enzymes as a therapeutic agent for the treatment of (c) 2011-14, JDDT. All Rights Reserved tumor $^{5}$. L-glutaminase is a cellular enzyme that deaminates the l-glutamine. It also acts as an endopeptidase, which hydrolyses the peptide bond present in the interior of the protein molecules. glutaminases are ubiquitous in the biological world ${ }^{6}$

On an industrial scale, glutaminases are produced mainly by Aspergillusand Trichodermasp. ${ }^{7,8}$. F . From an industrial point of view, filamentous fungi are particularly interesting as producers of glutaminase because they excrete substantially greater amounts of glutaminolytic enzymes into an extra cellular culture medium than bacteria or yeasts. A variety of microorganisms, including bacteria, yeast, moulds and filamentous fungi have been reported to produce Lglutaminase of which the most potent producers are fungi (Balagurunathan et al., 2010).

Keeping in view the extensive industrial importance of the L-glutaminase, a study was carried out forfungal glutaminases, it is thought that if extracellular glutaminases are able to be found, they will be produced more easily, in order to meet the growing industrial demands (Nathiya et al., 2011). The objective of this study was to produce enhanced level of L-glutaminase synthesis by supplementing carbon and nitrogen sources by using Aspergillusoryzaewith submerged fermentation.

\section{MATERIALS AND METHODS}

\section{Chemicals}

Glutamine used in the study was procured from $\mathrm{Hi}$ Media Laboratories, Bombay, India; the other 
ingredients used for the preparation of CzapekDox's media were also products of Hi-Media Laboratories, Bombay.

\section{Fungal strain}

Thirty isolates of Aspergillusoryzaestrains were isolated from different soils. Soils are taken from different regions from Vijayawada..Tentatively identified in the laboratory and further the strains were identified at Agarkar research Institute (ARI), Pune.

\section{Screening of the isolates}

Aspergillusoryzae strains were screened for their Lglutaminase activity by plate assay and among the thirty isolates, AspergillusoryzaeS2 were used for further studies.

\section{Studies for the production of L-glutaminase}

The selected AspergillusoryzaeS2 were cultured on production medium. The production medium consists of dextrose $0.1 \%$, yeast extract $0.3 \%, \mathrm{KCl} 0.02 \%, \mathrm{NaCl}$, $0.01 \%, \mathrm{MgCl}_{2} 0.02 \%$ and starch $0.5 \%$ w/v. The production medium set with $\mathrm{pH} 5$ and prepared flasks were cotton plugged and autoclaved at $121^{0} \mathrm{C}$ for $15 \mathrm{~min}$. The flasks were inoculated $0.75 \mathrm{ml}$ of inoculum and incubated at $35^{\circ} \mathrm{C}$

\section{Process Economization}

The proper supplementation of desired nutrients and nutrients and favorable conditions are necessary for growth and physiological activities of an organism. The above said nutrients were provided for enzyme production/ product formation.

The production medium were supplemented Carbon sources like glucose, fructose and sucrose in the range of $0.25 \%, 0.50 \%, 0.75 \%$, and $1.0 \%$ and nitrogen sources

\section{Extraction of L-glutaminase:}

The samples were withdrawn periodically at $24 \mathrm{hrs}$ in aseptic condition. The extract was filtered through Whatman filter No.1. The clear extract was centrifuged at 2000-3000 rpm for $15 \mathrm{~min}$, supernatant were used as enzyme preparation. Thus prepared crude enzyme was used for assay of L-glutaminase.

\section{Assay of L-glutaminase:}

Assay of L-glutaminase was carried out as per Imad et al. $(1973)^{12}$.L-glutamine were used as a substrate and the product ammonia were released during catalysis and it was measured by using Nesseler's reagent. The enzyme activity was expressed in International unit.

\section{International unit (IU):}

One IU of L-glutaminase is the amount of enzyme which liberates $1 \mu \mathrm{mol}$ of ammonia per minute per $\mathrm{ml}[\mu$ $\mathrm{mole} / \mathrm{ml} / \mathrm{min}]$.

\section{RESULTS AND DISCUSSION}

Fungal isolates were identified as Aspergillusoryzaein Agrakar Research Institute, Pune. All thirty strains of Aspergillus oryzaeproduced pink zones on glutamine plate medium; those were selected from the soil sample. Of the thirty isolates Aspergillus oryzae S2was considered to be the best and high L-glutaminase producing strain. The data obtained in the present study on the effect of $\mathrm{pH}$, temperature and inoculum size on submerged fermentation is shown 217.65 IU.

Incorporation of additional carbon source to the production medium was carried out to achieve maximum yield of L-glutaminase. Here we used different carbon source Such as Glucose, Fructose and sucrose in the range of $0.25 \%, 0.5 \%, 0.75 \%$ and $1.0 \%$ level were used for the maximum production of L-glutaminase.

The results on the studies pertaining to the production of L-glutaminase by Aspergillusoryzae KGSD 02 on synthetic medium supplemented with different concentrations of various carbon sources like glucose (monosaccharide), fructose (monosaccharide) and lactose (disaccharide) are presented in Fig, 1 Fig,2 and Fig,3 respectively. The process economization for Lglutaminase production with carbon sources supplemented to the production medium were carried out with concentration of $0.25 \%, 0.5 \%, 0.75 \%, 1.0 \%$ and $1.25 \%$. The results revealed that all the carbon sources employed under the present study have enhanced the production of L-glutaminaseupto $0.5 \%$ and $1 \%$ of monosaccharide (glucose and fructose) and $1 \%$ of disaccharides (lactose) respectively at $72 \mathrm{hrs}$ of fermentation, thereafter no significant production of Lglutaminase was observed on all the days of fermentation period. In case of monosaccharides (fructose) the maximum L-glutaminase production of 494.1 IU was observed at $1 \%$ and Where as disaccharides like lactose yielded maximum L-glutaminase of 343.5 IU. 


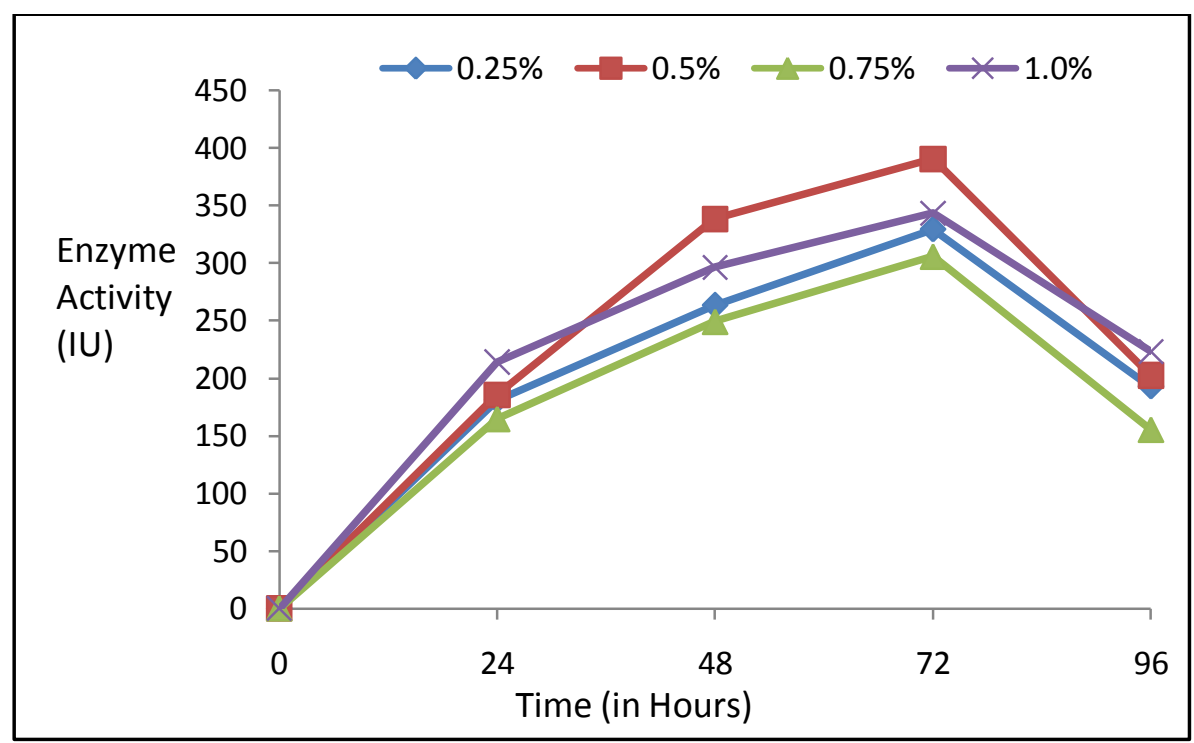

Fig 1: Effect of Glucose on L-glutaminase production

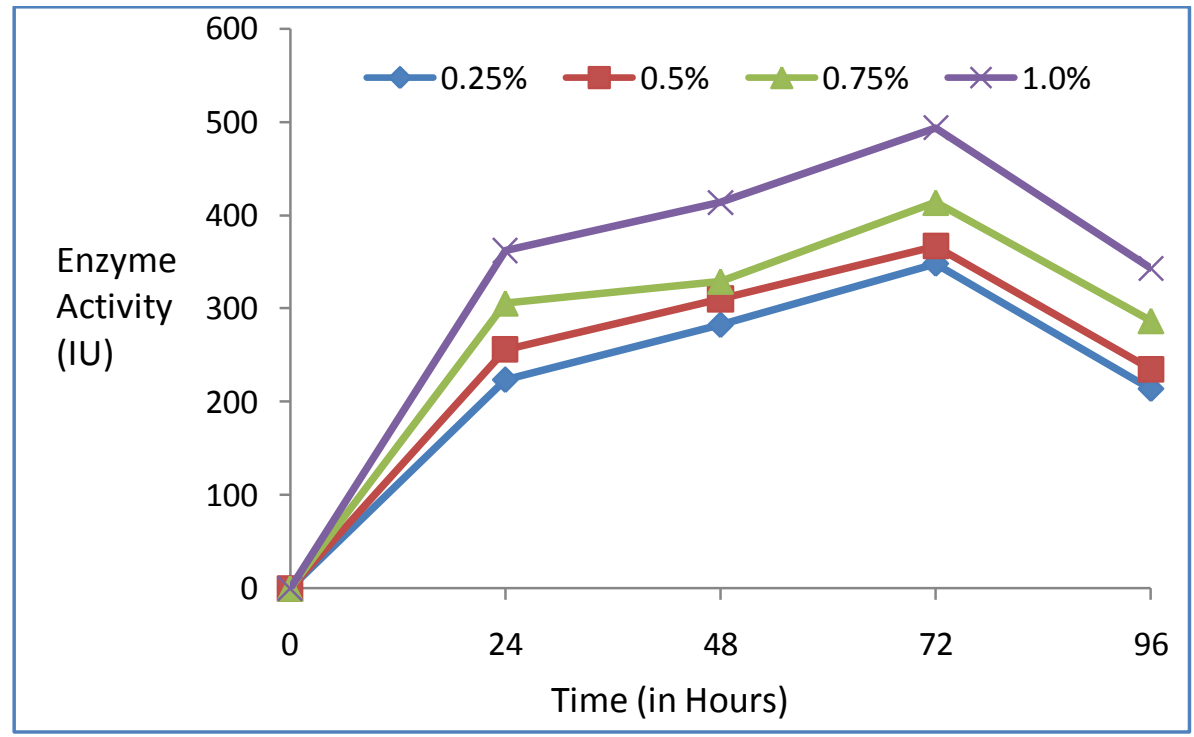

Fig 2: Effect of Fructose on L-glutaminase production

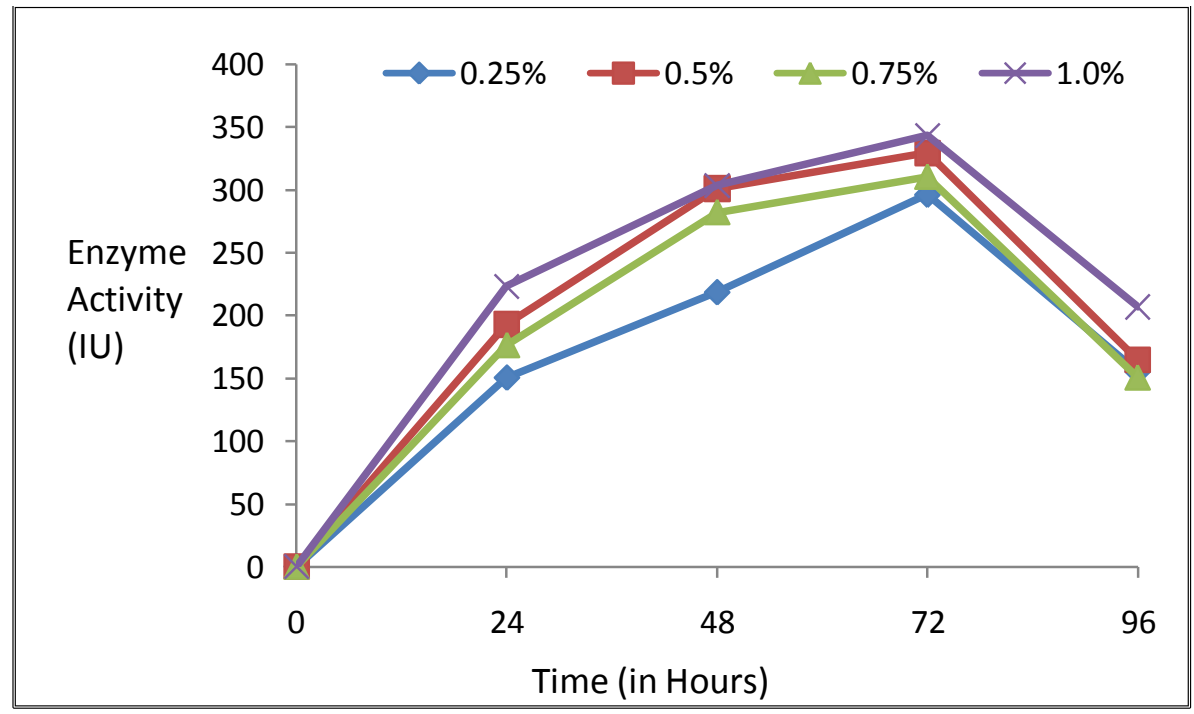

Fig 3: Effect of Lactose on L-glutaminase production 
The main product of the fermentation process will often determine the choice of carbon source, particularly if the product results from the direct dissimilation of it. Energy for growth comes from either the oxidation of the medium components or from light. Most industrial microbes utilize the commonest form of energy in the form of carbon sources such as carbohydrates, lipids and proteins. It is a common practice to use carbohydrates as the carbon source in microbial fermentation processes. The rate at which the carbon source is metabolized often influences the formation of biomass or production of primary or secondary metabolites ${ }^{13}$.

\section{REFERENCE}

1. Nagwa Ahmed Abdallah, ShaimaaKhairyAmer and Mario Khalil Habeeb, Production, Purification and Characterization of LGlutaminase enzyme from Streptomyces avermitilis, Afr. J. Microbiol. Res., 2013; Vol. 7(14), ISSN 1996-0808, pp. 1184-1190.

2. Souba WW, Glutamine and cancer. Ann. Surg., 1993, 218: 715-728.

3. Klein M, Kaltwasser $\mathrm{H}$ and Jahns T. FEMS MicrobiolLett 2002; 206: 63-67

4. Iyer P, Singhal RS. Glutaminase production using Zygosaccharomycesrouxii NRRL-Y 2547: Effect of aeration, agitation regimes and feeding strategies. Chem. Eng. Technol., 2010, 33: 52-62.

5. Holcenberg JS Enzyme Therapy: Problems and Solutions. Ann Rev Biochem 1982; 51: 795-812.

6. Ohshima M, Yamamoto T, Soda K, Effect of Glutamine analogs on glutaminase formation in Pseudomonas aeruginosa. Bull. Inst. Chem. Res. Kyoto Univ., 1976a, 54: $170-175$.

7. Tomita K, Yano T, Kumagai H and Tochikura T. J Ferment Technol 1998; 66: 299-304.

8. Masuoa N, Itob $\mathrm{K}$, Yoshimunea $\mathrm{K}$, Hoshinoa M, Matsushimab H, Koyamab Y and Moriguchia M. PtnExpPur, 2004; 38: 272-278.

9. El-Sayed ASA. Ind J Microbiol 2009; 4: 243-250.
HiremathJyothi et al (2011) $)^{14}$ reported maximum Lglutaminase production from a synthetic medium supplemented with $1 \%$ glucose with Pseudomonas as the fermenting organism. Chitanand and Shete $(2012)^{15}$ have also reported L-glutaminase production to be maximum when the medium was supplemented with $1 \%$ glucose.Jayabalan et al., (2010) were reported that the fructose showed $34.0 \mathrm{U} / \mathrm{ml}$ of L-glutaminase were showed. Our results from the study is in agreement with the results of Jayabalan et al., $(2010)^{16}$.

10. Balagurunathan R Radhakrishnan M. SomasundaramST. Lglutaminase Producing Actinomycetes from Marine Sediments -Selective Isolation, Semi Quantitative Assay and Characterization of Potential Strain. Australian Journal of Basic and Applied Sciences, (2010). 4(5): 698-705,

11. Nathiya K, Sooraj SN, Angayarkanni J and Palaniswamy M. Int J Phar Biosci 2011; 2: 297- 302.

12. Imada, A., Igarasi, S., Nakahama, K.and Isono, M.. Asparagin ase and glutaminase activities of microorganisms.J. Gen. Microbiol., (1973), 76: 85-89.

13. Stanbury, P.F., Whitakar, A. and Hall, S.J. In: "Principles of Fermentation Technology", $2^{\text {nd }}$ Edition, Pergamon, USA, 1995. pp 1-31.

14. Hiremath Jyothi, Shivaveera kumar and Rathod Vandanau. Pr oduction of L-Glutaminase by Pseudomonas VJ6. Research Journal of Biotechnology.(2011) Vol 6(3).4249

15. Chitanand MP and Shete HG). Condition optimization and pr oduction of L-glutaminase fromPseudomonas fluorescens. (2012, Int J Pharm Bio Sci; 3(3) 155 -162.

16. Jayabalan $\mathrm{R}$, Jeeva $\mathrm{S}$, Sasikumar AP. Inbakandan D Swaminathan $\mathrm{K}$ and Yun SE. Extracellular L-glutaminase production by marineBrevundimonasdiminutamtcc 8486. International Journal on Applied Bioengineering, 2010, Vol. 4, No.2, 19-24 